Supporting Information for:

\title{
Growth and Structure of Surface-Initiated Poly(n-alkylnorbornene) Films
}

Brad J. Berron, Evan P. Graybill, and G. Kane Jennings

There are several suppliers for norbornene. In the preparation of this manuscript, we used norbornene from two sources and observed differences between norbornene supplied from MP Biomedicals (99\%) and norbornene supplied from Acros (99\%). Monomers were used as received. Features similar to those seen in the Acros material have been observed by other research groups ${ }^{1,2}$ in norbornene (purity not specified by authors) supplied by Aldrich.
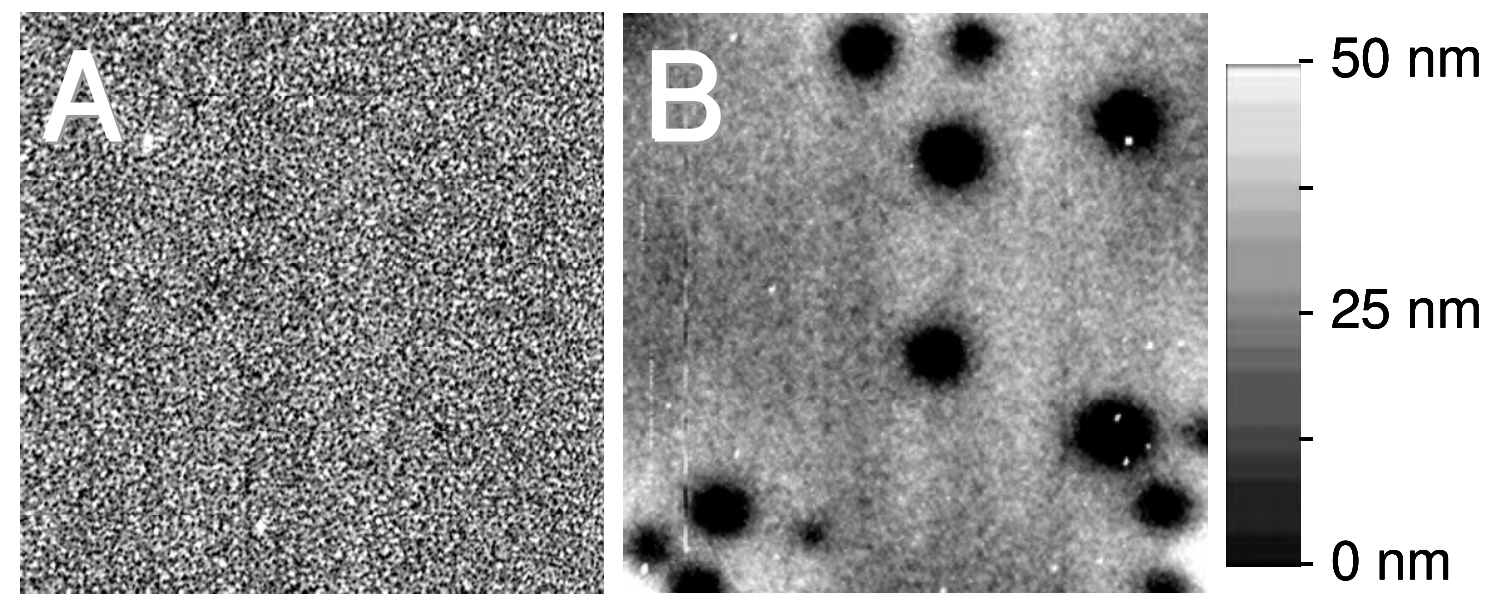

Figure S1. AFM images $(25 \mu \mathrm{m} \times 25 \mu \mathrm{m})$ of pNB films grown from norbornene from MP Biomedicals (A) and Acros (B).

Table S1. Film Capacitance, Resistance and Ellipsometric Thickness Values for pNB films

\begin{tabular}{lcccc}
\hline \multicolumn{1}{c}{ film } & $\begin{array}{c}\text { thickness } \\
(\mathrm{nm})\end{array}$ & $\begin{array}{c}\log \left(\mathrm{R}_{\mathrm{f}}\right) \\
\left(\Omega \bullet \mathrm{cm}^{2}\right)\end{array}$ & $\begin{array}{c}\mathrm{C}_{\mathrm{f}} \\
\left(\mathrm{nF} / \mathrm{cm}^{2}\right)\end{array}$ & $\begin{array}{c}\mathrm{Z}_{\mathrm{w}} \\
\left(\Omega \bullet \mathrm{s}^{-1 / 2}\right)\end{array}$ \\
\hline pNB - MP Biomedicals & $49 \pm 2$ & $4.3 \pm 0.6$ & $250 \pm 170$ & $11000 \pm 17000$ \\
pNB - Acros & $41 \pm 5$ & $2.9 \pm 0.4$ & $790 \pm 300$ & $490 \pm 260$
\end{tabular}

References:

(1) Rutenberg, I. M.; Scherman, O. A.; Grubbs, R. H.; Jiang, W.; Garfunkel, E.; Bao, Z. J. Am. Chem. Soc. 2004, 126, 4062-4063.

(2) Rutenberg, I. M. Functionalized Polymers and Surfaces via Ring-Opening Metathesis Polymerization; California Institute of Technology: Pasadena, CA, 2005. 